\title{
Sistem Informasi Geografis Pencarian Lokasi Kafe di Medan Menerapkan Algoritma Tabu Search (TS)
}

\author{
Julianti \\ Program Studi Teknik Informatika, STMIK Budi Darma, Medan, Indonesia
}

\begin{abstract}
Abstrak-Bisnis kafe di Kota Medan saat ini sedang berkembang sangat pesat. Hal ini dapat dilihat banyaknya kafe yang bermunculan, dikarenakan kafe sudah menjadi lifestyle bagi kebanyakan orang di jaman sekarang. Keberadaan lokasi kafe di kota medan sangat banyak dan hampir disetiap kota medan terdapat kafe yang lebih dari satu. Karena jumlahnya yang menyebar membuat orang menjadi bingung bahkan tidak tahu letak-letak keberadaan lokasi kafe tersebut. Mengharuskan adanya suatu sistem untuk melakukan pengecekan lokasi yang dituju. Berdasarkan permasalahan tersebut maka penulis akan membahas tentang pembuatan Sistem Informasi Geografis Pencarian Lokasi Kafe Di Kota Medan Dengan Menggunakan Algoritma Tabu Search. Sistem ini dibuat dengan menggunakan berbasis android, Dimana didalam sistem ini terdapat informasi lokasinya, yang terdiri dari alamat, serta jalur rute yang dapat digunakan untuk menuju lokasi kafe tersebut. Dalam proses ini hanya admin yang dapat memproses input data, edit data dan hapus data. Sedangkan user hanya dapat melihat mencari informasi lokasi kafe yang ada di kota medan. Dengan tampilan sistem yang sederhana dan mudah dipahami masyarakat dalam mengakses informasi pencarian lokasi kafe dapat digunakan sebagai upaya pengenalan teknologi berbasis sistem informasi geografis kepada masyarakat.
\end{abstract}

Kata Kunci: Sistem Informasi Geografis, Algoritma Tabu Search

\begin{abstract}
The cafe business in Medan is currently growing very rapidly. This can be seen by the many cafes that have sprung up, because cafes have become a lifestyle for most people today. The existence of the location of cafes in the city of Medan very much and almost every city of Medan there are more than one cafe. Because the amount that spreads makes people confused even do not know the location of the location of the cafe. Requires a system to check the intended location. Based on these problems, the writer will discuss about making a Geographic Information System for Locating Cafe Locations in the City of Medan Using the Tabu Search Algorithm. This system is made using Android-based, where in this system there is location information, consisting of an address, as well as route routes that can be used to get to the location of the cafe. In this process only the admin can process input data, edit data and delete data. While users can only look for information on the location of cafes in the city of Medan. With a simple and easy-to-understand system for the public to access information on the search for cafe locations, it can be used as an effort to introduce technology based on geographic information systems to the public.
\end{abstract}

Keywords: Sistem Informasi Geografis, Algoritma Tabu Search

\section{PENDAHULUAN}

Sistem Informasi Geografis (SIG) atau yang juga dikenal dengan Sistem Informasi keruangan adalah sistem informasi berbasis komputer yang digunakan untuk mengumpulkan, menyimpan, menggabungkan, mengatur, mentransformasi, memanipulasi dan menganalisis data yang bergeoreferensi. Sistem Informasi Geografis (SIG) akan menghasilkan informasi yang lebih berkualitas dan informasi yang disajikan tersebut dapat dengan mudah dipahami oleh pengguna, sesuai dengan perkembangan ilmu pengetahuan dan teknologi terkini pembuatan peta pun bisa dilakukan tidak dengan cara konvensional (sederhana).

Perkembangan bisnis kafe di Kota Medan saat ini sedang berkembang sangat pesat. Hal ini dapat dilihat banyaknya kafe yang bermunculan, dikarenakan kafe sudah menjadi lifestyle bagi kebanyakan orang di jaman sekarang. Demi membuat kafe ramai dikunjungi orang, para pengelolah menerapkan berbagai cara untuk menarik perhatian para pengunjung dengan desain yang bagus. Hal ini juga dapat dilakukan dengan memberikan harga yang sesuai, memberikan pelayanan yang maksimal serta menawarkan suasana yang nyaman dan menyenangkan.

Adapun masalah yang timbul dalam pencarian lokasi kafe saat ini adalah. Keberadaan lokasi kafe di kota medan sangat banyak dan hampir disetiap tempat terdapat kafe yang lebih dari satu. Karena jumlahnya yang menyebar membuat orang menjadi bingung bahkan tidak tahu letak-letak keberadaan lokasi kafe tersebut. Dan mengharuskan adanya suatu sistem untuk melakukan pengecekan lokasi yang dituju. Dimana di dalam sistem ini terdapat informasi lokasinya, yang terdiri dari alamat, serta lokasi yang dapat digunakan untuk menuju kafe tersebut dengan menggunakan algoritma tabu search berbasis android.

Tabu Search merupakan salah satu algoritma yang berada dalam ruang lingkup metode heuristik. Algoritma ini menggunakan memory untuk menjaga agar proses pencarian tidak terjebak pada nilai optimum lokal. Algoritma ini menggunakan tabu list untuk menyimpan sekumpulan solusi yang baru saja di evaluasi. Selama proses optimasi pada setiap iterasi, solusi yang akan dievaluasi akan dicocokkan terlebih dahulu dengan isi tabu list untuk melihat apakah solusi tersebut sudah ada pada tabu list [1]. Dalam proses optimasi ini dengan cara kerja untuk mendapatkan hasil maksimum atau minimum dari satu fungsi yang tertentu Dengan penyelesaian masalalahnya yang optimal sesuai dengan masalah yang harus dipenuhi.

\section{METODE PENELITIAN}

\subsection{Sistem Informasi Geografis}

Julianti, Copyright @ 2019, JSON, Page 14 
Sistem Informasi Geografi (SIG) merupakan suatu sistem informasi yang didesain untuk bekerja dengan data yang direferensikan oleh spasial atau koordinat geografi yang terkomputerisasi. Dengan kata lain, Sistem Informasi Geografi (SIG) adalah sistem informasi berbasis komputer yang digunakan untuk mengolah dan menyimpan data atau informasi geografis [2]. Sistem informasi geografis dapat kita simpulkan sebagai gabungan kartografi.

Komponen-komponen yang membangun sebuah sistem informasi geografis adalah [2]:

1. Computer System and Software

Merupakan sistem computer dan kumpulan piranti lumak yang digunankan untuk mengelolah data.

2. Spesial data

Merupakan data spesial (bereferensi keruangan dan kebumian) yang akan diolah.

3. Data Management and Analysis Procedure

Managemen data dan analisa prosedur oleh database management system.

4. People

Entitas sumber data manusia yang akan mengoperasikan sistem informasi geografis.

\subsection{Konsep Real Word}

Konsep real word merupakan sebuah cara bagaimana SIG mengubah realitas fisik sebuah dunia menggunakan model menjadi sebuah sistem informasi geografis yang dapat disimpan, dimanipulasi, diproses dan dipresentasikan [2].

Konsep real word memiliki beberapa tahapan sebagai berikut:

1. Physicial Reality

Merupakan tahapan di mana menganalisa dunia nyata yang akan dibuat menjadi SIG.

2. Real Word Model

Tahapan mengubah obyek-obyek yang ada di dunia nyata menjadi model.

3. Data Model

Tahapan yang mengubah model-model obyek dunia nyata menjadi sebuah tipe data.

4. Database

Menyimpan keseluruhan data model ke dalam sistem basis data.

5. Maps/Reports

Merupakan hasil akhir dunia nyata yang telah dikonversi menjadi sebuah sistem informasi geografis. menggunakan model menjadi sebuah sistem informasi geografis

\subsection{Jalur Terpendek}

Proses penghitungan rute terpendek adalah proses mencari jarak terpendek atau biaya terkecil suatu rute dari node awal ke node tujuan dalam sebuah jaringan. Pada proses penghitungan rute terpendek terdapat dua macam proses yaitu proses pemberian label dan proses pemeriksaan node. Metode pemberian label adalah metode untuk memberikan identifikasi pada setiap node dalam jaringan. Pada sebagian besar algoritma penghitungan rute terpendek, terdapat 3 label informasi yang dikelola untuk setiap node i pada proses pemberian label yaitu: label jarak d (i), parentnode $\mathrm{p}(\mathrm{I})$, dan status node $\mathrm{S}$ (i) [3].

\subsection{Kafe}

Kafe berasal dari bahasa Perancis yaitu cafe yang berarti coffee, dalam bahasa Indonesia kopi atau coffe house dalam bahasa Indonesia kedai kopi, istilah ini muncul pada abad ke 18 di Inggris. Kafe (cafe) yang pertama dibuka di Constantinople, ibu kota kerajaan Kerajaan Ottoman, Turki, pada tahun 1555. Ini bertepatan dengan pembukaan toko yang menyediakan kopi, di distrik Tahtakale oleh Hakam dan Shams, imigran Turki dari Aleppo Cafe (Kafe) [4].

\subsection{Google Maps API}

Maps adalah aplikasi dan teknologi layanan pemetaan berbasis web yang menampilkan citra satelit beresolusi tinggi untuk peta jalan, rute sepeda, pejalan kaki, mobil serta penentuan lokasi bisnis di kota-kota berbagai negara seluruh dunia yang di sediakan oleh DigitalGlobe dengan satelitnya QuickBird, serta data dari Geographic Information System (GIS) buatan Tele Atlas, NAVTEQ, dan MapABC [5].

\subsection{Algoritma Tabu Search}

Algoritma Tabu Search merupakan salah satu algoritma yang berada dalam ruang lingkup metode heuristik. Algoritma ini menggunakan short-term memory untuk menjaga agar proses pencarian tidak terjebak pada nilai optimum lokal. Algoritma ini menggunakan tabu list untuk menyimpan sekumpulan solusi yang baru saja dievaluasi. Selama proses optimasi pada setiap iterasi, solusi yang akan dievaluasi akan dicocokkan terlebih dahulu dengan isi tabu list untuk melihat apakah solusi tersebut sudah ada pada tabu list [6].

Langkah-langkah kerja dari algoritma Tabu Search pada aplikasi simulasi penentuan rute terpendek lokasi kafe di Kota Medan yaitu [7]: 
1. Inisial variabel titik awal atau lokasi awal tempat kafe yang ingin dikunjungi dan titik akhir atau lokasi akhir tempat kafe yang ingin dikunjungi.

2. Kemudian inisial MaxIterasi yang merupakan jumlah iterasi yang akan dilakukan dalam pencarian rute.

3. Mulai dengan sebuah solusi awal dengan indeks solusi pertama. Solusi awal diperoleh dari tahap inisialisasi dan merupakan jalur awal yang diperoleh secara acak. Selanjutnya dilakukan proses perulangan membandingkan setiap titik sampai titik tujuan yang dipilih dan memilih secara acak titik mana saja yang bisa dilewati untuk menjadi rute solusi awalnya.

4. Akan dihitung total jaraknya (panjang). Solusi awal yang telah diperoleh akan dimasukkan dalam tabu list.

5. Proses selanjutnya menginisialisasi solusi Tabu Search. Jalur yang ada pada proses pencarian akan dilakukan iterasi dengan menukarkan posisi setiap jalur untuk mendapatkan rute alternatifnya.

6. Kemudian dilakukan proses penghitungan setiap jaraknya. Jika jarak solusi lebih kecil dari total jarak solusi awal (p < pnjg), maka solusi2 masuk ke dalam tabu list dan dilakukan proses iterasi selanjutnya.

7. Rute terpendek yang didapat dari hasil proses pencarian tersebut akan ditampilkan pada peta.

\title{
3. ANALISA DAN PEMBAHASAN
}

Keberadaan lokasi kafe di kota medan saat ini sangat banyak, Dan dikarenakan keberadaannya menyebar mengharuskan adanya suatu sistem, dimana didalam sistem ini terdapat informasi dan pengecekan jalur rute dan lokasi yang dituju. Maka dari itu untuk melihat lokasi kafe dengan detail di handphone, mungkin tidak asing lagi dengan program dari google, yaitu google maps, dengan itu bisa mengetahui perkiraan posisi kita berada, dan mulai posisi keberadaan sampai tujuan. Seperti posisi awal dari STMIK BUDI DARMA menuju kafe terdekat.

\section{Langkah 1 :}

Inisial variabel titik awal atau lokasi awal tempat kafe yang ingin dikunjungi dan titik akhir atau lokasi akhir tempat kafe yang ingin dikunjungi.

\author{
Posisi : STMIK BUDIDARMA \\ A : $\quad$ Cafe Mila \\ Alamat : Jl. Sisingamangaraja \\ B : $\quad$ Cafe Kembar \\ Alamat : Sakti Lubis \\ C : $\quad$ Cafe Garnis \\ D : $\quad$ I-Gallery Cafe \\ Alamat: Jl. Sisingamangaraja \\ E : $\quad$ Amizu Cafe \& Coffe \\ Alamat : Sakti Lubis \\ F : $\quad$ Cafe Kombur \\ Alamat : Jl. Sisingamangaraja \\ G : D'Caldera Coffe \\ Alamat : J1. Sisingamangaraja
}

\section{Langkah 2 :}

Kemudian inisial MaxIterasi yang merupakan jumlah iterasi yang akan dilakukan dalam pencarian rute sebanyak 3 jalur.

\author{
Jalur $1: 43,56 \mathrm{M}+100,00 \mathrm{M}+412,76 \mathrm{M}+285,58 \mathrm{M}=850,9 \mathrm{M}$ \\ Jalur $2: 43,56 \mathrm{M}+145,36 \mathrm{M}+56,88 \mathrm{M}+412,76 \mathrm{M}+285,58 \mathrm{M}=6.584,26 \mathrm{M}$ \\ Jalur 3: 40,432M+581,34M+56,88M + 412,76M + 285,58M $=1.376,991 \mathrm{M}$
}

\section{Langkah 3 :}

Mulai dengan sebuah solusi awal dengan indeks solusi pertama. Solusi awal diperoleh dari tahap inisialisasi dan merupakan jalur awal yang diperoleh secara acak. Selanjutnya dilakukan proses perulangan membandingkan setiap titik sampai titik tujuan yang dipilih dan memilih secara acak titik mana saja yang bisa dilewati untuk menjadi rute solusi awalnya.

1. Posisi $\longrightarrow \mathrm{A}$

$$
\begin{aligned}
& \text { Jalur } 1: 43,56 \mathrm{M}+100,00 \mathrm{M}+412,76 \mathrm{M}+285,58 \mathrm{M}=850,9 \mathrm{M} \\
& \text { Jalur } 2: 43,56 \mathrm{M}+145,36 \mathrm{M}+56,88 \mathrm{M}+412,76 \mathrm{M}+285,58 \mathrm{M}=6.584,26 \mathrm{M} \\
& \text { Jalur } 3: 40,432 \mathrm{M}+581,34 \mathrm{M}+56,88 \mathrm{M}+412,76 \mathrm{M}+285,58 \mathrm{M}=1.376,991 \mathrm{M}
\end{aligned}
$$


2. Posisi $\longrightarrow \mathrm{B}$

Jalur $1: 40,432 \mathrm{M}+581,34 \mathrm{M}+598,69 \mathrm{M}+=1.220,461 \mathrm{M}$

Jalur $2: 43,56 \mathrm{M}+145,36 \mathrm{M}+581,34 \mathrm{M}=770,26 \mathrm{M}$

Jalur $3: 43,56 \mathrm{M}+145,36 \mathrm{M}+14,451 \mathrm{M}+292,55 \mathrm{M}+703,16 \mathrm{M}+598,69 \mathrm{M}$ $=1.797,771 \mathrm{M}$

3. Posisi $\longrightarrow \mathrm{C}$

Jalur $1: 43,56 \mathrm{M}+100,00 \mathrm{M}+412,76 \mathrm{M}+285,58 \mathrm{M}+358,62 \mathrm{M}+372,56 \mathrm{M}=1.573,08 \mathrm{M}$

Jalur $2: 43,56 \mathrm{M}+100,00 \mathrm{M}+412,76 \mathrm{M}+285,58 \mathrm{M}+358,62 \mathrm{M}+552,64 \mathrm{M}+667,38 \mathrm{M}+199,22 \mathrm{M}+$ $928,37 \mathrm{M}+372,56=3.288,69 \mathrm{M}$

Jalur $3: 43,56 \mathrm{M}+145,36 \mathrm{M}+56,88 \mathrm{M}+412,76 \mathrm{M}+285,58 \mathrm{M}+358,62 \mathrm{M}+372,56 \mathrm{M}=1.675,32 \mathrm{M}$

4. Posisi $\longrightarrow \mathrm{D}$

Jalur $1: 43,56 \mathrm{M}+100,00 \mathrm{M}+212,06 \mathrm{M}+294,86 \mathrm{M}=650,48 \mathrm{M}$

Jalur $2: 40,431 \mathrm{M}+581,34 \mathrm{M}+145,36 \mathrm{M}+43,56 \mathrm{M}+100,00 \mathrm{M}+212,06 \mathrm{M}+294,86 \mathrm{M}=1.417,611 \mathrm{M}$

Jalur $3: 40,431 \mathrm{M}+581,34 \mathrm{M}+598,69 \mathrm{M}+703,16 \mathrm{M}+292,55 \mathrm{M}+14,451 \mathrm{M}+145,36 \mathrm{M}+43,56 \mathrm{M}+$ $100,00 \mathrm{M}+212,06 \mathrm{M}+294,86 \mathrm{M}=3.026,462 \mathrm{M}$

5. Posisi $\longrightarrow \mathrm{E}$

Jalur $1: 40,431 \mathrm{M}+581,34 \mathrm{M}=621,771 \mathrm{M}$

Jalur $2: 43,56 \mathrm{M}+145,36 \mathrm{M}+581,34 \mathrm{M}=770,26 \mathrm{M}$

Jalur $3: 40,431 \mathrm{M}+581,34 \mathrm{M}+598,69 \mathrm{M}+703,16 \mathrm{M}+292,55 \mathrm{M}+14,451 \mathrm{M}+145,36 \mathrm{M}+43,56 \mathrm{M}+$ $212,06 \mathrm{M}+294,86 \mathrm{M}=3.026,462 \mathrm{M}$

6. Posisi $\longrightarrow \mathrm{F}$

Jalur $1: 43,56 \mathrm{M}+100,00 \mathrm{M}+412,76 \mathrm{M}+285,58 \mathrm{M}+358,62 \mathrm{M}+372,56 \mathrm{M}+928,37 \mathrm{M}+606,49 \mathrm{M}=$ $3.107,94 \mathrm{M}$

Jalur $2: 43,56 \mathrm{M}+100,00 \mathrm{M}+412,76 \mathrm{M}+285,58 \mathrm{M}+358,62 \mathrm{M}+552,64 \mathrm{M}+667,38 \mathrm{M}+199,38 \mathrm{M}+$

7. Posisi $\longrightarrow \mathrm{G}$ $928,22 \mathrm{M}+606,49 \mathrm{M}=4.154,62 \mathrm{M}$

Jalur $1: 43,56 \mathrm{M}+100,00 \mathrm{M}+412,76 \mathrm{M}+285,58 \mathrm{M}+358,62 \mathrm{M}+372,56 \mathrm{M}+928,37 \mathrm{M}+606,49 \mathrm{M}+$ $835,52 \mathrm{M}=3.943,46 \mathrm{M}$

Jalur $2: 43,56 \mathrm{M}+100,00 \mathrm{M}+412,76 \mathrm{M}+285,58 \mathrm{M}+358,62 \mathrm{M}+552,64 \mathrm{M}+667,38 \mathrm{M}+199,38 \mathrm{M}+$ $928,22 \mathrm{M}+606,49 \mathrm{M}+835,52 \mathrm{M}=4.990,14 \mathrm{M}$

Jalur $3: 43,56 \mathrm{M}+145,36 \mathrm{M}+56,88 \mathrm{M}+412,76 \mathrm{M}+285,58 \mathrm{M}+358,62 \mathrm{M}+372,56 \mathrm{M}+928,37 \mathrm{M}+$ $606.49 \mathrm{M}+835,52 \mathrm{M}=4.045,7 \mathrm{M}$

Langkah 4 :

Kemudian solusi awal yang diperoleh akan dihitung total jaraknya (panjang). Solusi awal yang telah diperoleh akan dimasukkan dalam tabu list.

Tabel 1. Tabu List

\begin{tabular}{lll}
\hline TUJUAN & $\begin{array}{l}\text { KEDEKATAN } \\
\text { (SIMILARITY) }\end{array}$ & RUTE \\
\hline \multirow{3}{*}{ A } & Jalur 1 & $850,9 \mathrm{M}$ \\
& Jalur 2 & $770,26 \mathrm{M}$ \\
& Jalur 3 & $1.376,991 \mathrm{M}$ \\
B & Jalur 1 & $1.220,461 \mathrm{M}$ \\
& Jalur 2 & $770,26 \mathrm{M}$ \\
& Jalur 3 & $1.797,771 \mathrm{M}$ \\
C & Jalur 1 & $1.573,08 \mathrm{M}$ \\
& Jalur 2 & $3.288,69 \mathrm{M}$ \\
& Jalur 3 & $1.675,32 \mathrm{M}$ \\
D & Jalur 1 & $650,48 \mathrm{M}$ \\
& Jalur 2 & $1.417,611 \mathrm{M}$ \\
& Jalur 3 & $3.026,462 \mathrm{M}$ \\
E & Jalur 1 & $621,771 \mathrm{M}$ \\
& Jalur 2 & $770,26 \mathrm{M}$ \\
F & Jalur 3 & $3.026,462 \mathrm{M}$ \\
& Jalur 1 & $3.107,94 \mathrm{M}$ \\
\multirow{2}{*}{ G } & Jalur 2 & $4.154,62 \mathrm{M}$ \\
& Jalur 1 & $3.943,46 \mathrm{M}$ \\
& Jalur 2 & $4.990,14 \mathrm{M}$ \\
\hline
\end{tabular}

\section{Langkah 5 :}


Proses selanjutnya menginisialisasi solusi Tabu Search. Jalur yang ada pada proses pencarian akan dilakukan iterasi dengan menukarkan posisi setiap jalur untuk mendapatkan rute alternatifnya.

Tabel 2. Jalur Rute Terdekat

\section{Langkah 6 :}

\begin{tabular}{ll}
$\begin{array}{l}\text { KEDEKATAN } \\
\text { (SIMILARITY) }\end{array}$ & RUTE \\
\hline Jalur A & $850,9 \mathrm{M}$ \\
Jalur B & $6.584,26 \mathrm{M}$ \\
Jalur C & $1.573,08 \mathrm{M}$ \\
Jalur D & $650,48 \mathrm{M}$ \\
Jalur E & $770,26 \mathrm{M}$ \\
Jalur F & $3.107,94 \mathrm{M}$ \\
Jalur G & $3.943,46 \mathrm{M}$ \\
\hline
\end{tabular}

Kemudian dilakukan proses penghitungan setiap jaraknya. Jika jarak solusi lebih kecil dari total jarak solusi awal ( $\mathrm{p}<$ pnjg), maka solusi2 masuk ke dalam tabu list dan dilakukan proses iterasi selanjutnya.

Tabel 3. Penghitungan Jarak Terkecil

\begin{tabular}{ll}
\hline NO & Tabu List \\
\hline Jalur A & $850,9 \mathrm{M}$ \\
Jalur B & $770,26 \mathrm{M}$ \\
Jalur C & $1.573,08 \mathrm{M}$ \\
Jalur D & $650,48 \mathrm{M}$ \\
Jalur E & $770,26 \mathrm{M}$ \\
Jalur F & $3.107,94 \mathrm{M}$ \\
Jalur G & $3.943,46 \mathrm{M}$ \\
\hline
\end{tabular}

Perbandingan Tabu List dari jarak posisi STMIK BUDI DARMA ke posisi Kafe yaitu : posisi D yaitu 650,48M dan ke A yaitu 850,9M, maka jarak yang lebih kecil adalah jalur D 650,48M. Sedangkan posisi D yaitu 650,48M, dibandingkan dengan jalur B 770,26M, maka posisi D 650,48M yang terkecil, Posisi D 650,48M, dibandingkan dengan posisi C 1.573,08M, maka posisi D lebih kecil dari. Posisi D 650,48M. dibandingkan dengan posisi $\mathrm{E}$ $770,26 \mathrm{M}$, maka jarak yang lebih kecil adalah jalur D. Sedangkan dari posisi D ke posisi F 3.107,94M lebih kecil yaitu posisi D 650,48M, Dari posisi D 650,48M, dibandingkan dengan posisi G 3.943,46M, maka yang lebih kecil yaitu D 650,48M.

\section{Langkah 7 :}

Rute terpendek yang didapat dari hasil proses pencarian tersebut akan ditampilkan pada peta.

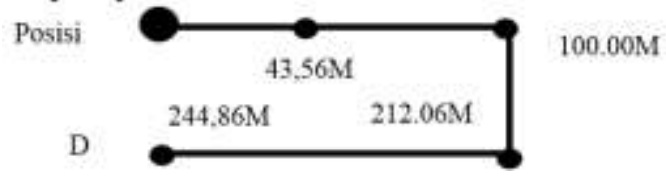

Gambar 1. Pencarian rute terpendek

\section{KESIMPULAN}

Berdasarkan hasil pembahasan yang telah dilakukan sebelumnya, maka dapat disimpulkan sebagai berikut:

1. Algoritma Tabu Search dapat digunakan untuk menyelesaikan permasalahan dalam pencarian lokasi kafe berbasis android.

2. Dengan menggunakan bahasa pemograman Java dan eclipse sebagai aplikasinya dapat membuat aplikasi pencarian lokasi kafe yang berbasis android dan memberikan hasil kepada pengguna lebih mudah dalam pencarian lokasi kafe terdekat.

\section{REFERENCES}

[1] L. Harlinda, "MEMBANTU PENCARIAN JALUR TERPENDEK MENUJU ATM BANK BRI DENGAN METODE TABU SEARCH ALGORITHM ( TS )," J. Ilm. Ilk., vol. 8, no. Desember, pp. 234-241, 2016.

[2] E. Irwansyah, Sistem Informasi Geografis : Prinsip Dasar dan Pengembangan Aplikasi. Yogyakarta, 2013.

[3] W. E. Yulia, "Pencarian Spbu Terdekat Dan Penentuan Jarak Terpendek Menggunakan Algoritma Dijkstra," J. Nas. Tek. 


\section{ISSN 2685-998X (Media Online)}

DOI: $10.30865 /$ json.v1i1.1366

Elektro, vol. 4, no. 1, pp. 89-93, 2015.

[4] E. H. S. Rojali Soni Afandi), "APLIKASI MOBILE INFORMASI KAFE 24 JAM DI YOGYAKARTA BERBASIS ANDROID,” J. Ilm. DASI Vol., vol. 14, no. 04, pp. 49-53, 2013.

[5] E. T. Prabowo, "Sistem Informasi Geografis Dalam Pencarian Lokasi Museum Di Daerah Istimewa Yogyakarta," vol. 1, no. 1, pp. 13-23, 2013.

[6] Hasugian, "PENGEMBANGAN APLIKASI UNTUK MEMPERMUDAH PENCARIAN,” vol. 2, no. 1, pp. 1-5, 2017.

[7] H. P. Sari, Simulasi Penentuan Rute Terpendek Menggunakan Metode Tabu Search (Studi Kasus : Lokasi Wisata di Palembang). Palembang. 